\title{
Financiamento da educação especial no município de Vitória: desafios à gestão
}

\section{Financing Special Education in the City of Vitória: Challenges for Management}

\author{
Marileide Gonçalves França* \\ Rosângela Gavioli Prieto**
}

\begin{abstract}
RESUMO
O objetivo é discutir desafios e possibilidades no processo de publicização dos recursos públicos voltados à educação especial no município de Vitória/ ES. Toma como referência a legislação educacional brasileira e as contribuições de autores que exploram interfaces entre financiamento e educação especial. Foram analisadas percepções de gestores educacionais, a partir de entrevista semiestrutura coletiva sobre receitas e despesas da educação, nesse município, e o planejamento orçamentário. Da análise do conteúdo foi possível evidenciar que os desafios vão do acesso aos dados, compreensão da linguagem contábil e de sua forma de registro, aos procedimentos vinculados à transparência de informações das verbas públicas destinadas à educação pela administração. Os gestores apontaram ações que não se restringiam somente às mudanças técnico-administrativas, mas também às alterações políticas que envolvem a gestão pública e seus procedimentos para a garantia de controle, acompanhamento e transparência dos recursos públicos dirigidos à educação especial.
\end{abstract}

Palavras-chave: Financiamento da educação. Educação especial. Administração pública. Transparência.

\footnotetext{
ABSTRACT

This study aims to discuss challenges and possibilities in the process of state ownership of public resources destined for special education in the city

* Universidade Federal do Espírito Santo. Vitória, Espírito Santo, Brasil. E-mail: leidemary8@yahoo.com.br. https://orcid.org/0000-0003-1690-6088.

** Universidade de São Paulo. São Paulo, São Paulo, Brasil. E-mail: rosangel@usp.br. https://orcid.org/0000-0003-4013-1163.
} 
of Vitória, ES, Brazil. It is based on Brazilian educational legislation and contributions from authors who explore the interfaces between financing and special education. Perceptions of educational managers have been analyzed, based on semi-structured group interviews about educational revenue and the expenditures in this municipality, as well as budget planning. Content analysis has highlighted that the challenges go from access to data, understanding of the accounting language and its form of registration, to procedures linked to the transparency of information about public funds allocated to education. The managers pointed out actions that were not limited to technical-administrative changes, but also involved political changes in public management and its procedures to guarantee control, monitoring and transparency of public resources allocated to special education.

Keywords: Education Funding. Special Education. Public Management Transparency.

\section{Introdução}

Este texto analisa desafios e possibilidades na gestão dos recursos públicos voltados à educação especial no município de Vitória/Espírito Santo (ES), a partir de percepções de gestores educacionais ${ }^{1}$ em relação ao desafio de garantir sua publicização. Desse modo, pretende-se contribuir com o aprofundamento das discussões referentes ao financiamento da educação especial, no que tange à gestão de recursos públicos.

O fomento à política de educação especial depende de investimento financeiro para garantir os insumos necessários ${ }^{2}$ ao atendimento escolar de pessoas com deficiência, transtornos globais de desenvolvimento (TGD) e altas habilidades/superdotação.

São exíguas as produções que abordam o financiamento dessa modalidade de ensino no Brasil (BENATTI, 2011; VIEGAS, 2014) e poucas pesquisas (PRIETO; GIL, 2011; GONZALEZ; PRIETO, 2012; FRANÇA, 2014; VIEGAS, 2014) voltam-se ao estudo do financiamento da educação especial nos sistemas públicos de ensino. Esses autores ressaltam a diminuta visibilidade dos dados

1 Profissionais que atuavam nos setores: educação infantil, ensino fundamental e educação especial; e nas gerências: administrativa, gestão democrática, recursos humanos, planejamento, formação e secretaria e finanças da Secretaria Municipal de Educação de Vitória.

2 Dentre esses insumos, podem ser citados, como parte dos serviços educacionais: as salas de recursos, os professores especializados e outros profissionais de apoio escolar, materiais e equipamentos específicos ou adaptados para proporcionar acesso ao conhecimento. 
referentes aos investimentos e aos gastos com essa modalidade de ensino nos balanços financeiros da educação.

De acordo com Viegas (2014), a falta de visibilidade dos recursos da educação especial nos balanços financeiros dos municípios pode, por um lado, ser interpretada de forma positiva, posto a matrícula desse alunado ser computada no conjunto das despesas da educação básica, o que é corroborado por diretrizes inclusivas, dispensando seu destaque em separado. Por outro lado, a não desagregação dificulta a avaliação sobre investimentos exclusivos na educação especial. Também implica em desconhecimento sobre os recursos correspondentes à segunda matrícula referente ao atendimento educacional especializado (AEE). Conhecer os gastos com essa modalidade é de extrema importância para subsidiar o planejamento e a avaliação, inerentes ao processo de gestão das políticas públicas (FRANÇA, 2014).

Neste artigo, primeiramente, discorre-se sobre a caracterização da educação especial no Brasil, a qual se segue a descrição metodológica, com a caracterização do município pesquisado, as análises dos discursos de gestores e as considerações finais.

\section{A educação especial no âmbito do Estado brasileiro}

O direito à educação de alunos com deficiência, TGD e altas habilidades/ superdotação, reconhecidos como potenciais alunos a serem matriculados também na educação especial (BRASIL, 2008, 2009), estabelecido na Constituição Federal (BRASIL, 1988) e ratificado na Lei de Diretrizes e Bases da Educação Nacional no 9.394 - LDB (BRASIL, 1996) e em normativas posteriores, constituiu-se como resultado de um processo de lutas de famílias, movimentos sociais, profissionais da educação, representantes políticos e sujeitos com deficiência. Assim, o Estado passa a assumir o dever de criar e implementar políticas públicas de cunho social, com destaque à educação. Segundo Garcia e Michels (2011, p. 116), há um movimento claro de intervenção estatal na política educacional no que se refere à essa modalidade de ensino, que se concretiza pela " [...] presença do Estado na criação de equipamentos públicos de educação especial" nas redes de ensino estaduais e municipais.

A Resolução n 2 (BRASIL, 2001), importante dispositivo legal que normatiza os princípios da educação inclusiva, presentes no debate internacional, destaca ações nos âmbitos político, técnico-científico, pedagógico e administrativo. Além disso, estabelece que os estados e municípios devem organizar, 
nas secretarias de educação, um setor responsável pelas questões da educação especial, dotado de recursos humanos, materiais e financeiros, visando à melhoria do seu atendimento.

Cumpre ressaltar que, no ano de 2007, tivemos a implantação do Fundo de Manutenção e Desenvolvimento da Educação Básica e de Valorização dos Profissionais da Educação (Fundeb), criado pela Emenda Constitucional $\mathrm{n}^{\mathrm{o}}$ 53/06 (BRASIL, 2006) e regulamentado pela Lei $n^{\circ}$ 11.494/07 (BRASIL, 2007a), e pelo Decreto $n^{\circ}$ 6.253/07 (BRASIL, 2007b), em substituição ao Fundo de Manutenção e Desenvolvimento do Ensino Fundamental e de Valorização do Magistério (Fundef). O Fundeb garante a destinação da maior parte dos recursos vinculados à educação básica, por meio de mecanismo de distribuição diferenciado por etapa e modalidade de ensino, e que tem por base as matrículas informadas no Censo Escolar do ano anterior. Na versão final do Fundeb, foram acrescentadas as matrículas de educação infantil e as da educação especial da rede conveniada sem fins lucrativos, garantindo a participação de verba pública nas instituições privadas sem fins lucrativos, especializadas e com atuação exclusiva em educação especial.

No final da primeira década dos anos 2000, foi publicado o documento Política Nacional de Educação especial na perspectiva da educação inclusiva (BRASIL, 2008) com orientações aos sistemas de ensino para a organização de serviços e recursos de educação especial de caráter complementar ou suplementar e reafirmada a educação especial como modalidade de ensino que deve ser transversal aos níveis e modalidades de ensino.

No intuito de garantir a implementação dessa política, que traduz certa expectativa em relação à ampliação de recursos e de serviços como apoio ao processo de escolarização desses alunos nas classes comuns da educação básica, foi aprovado o Decreto ${ }^{\circ}$ 7.611/11 (BRASIL, 2011), o qual altera o Decreto $\mathrm{n}^{\mathrm{0}} 6.253 / 07$ (BRASIL, 2007b) e normatiza a contabilização e o pagamento da dupla matrícula desses alunos, no âmbito do Fundeb, sendo uma correspondente à classe comum e a outra ao AEE. A oferta deste, contudo, pode ser realizada na mesma escola que o aluno frequenta ou em outra do seu entorno, ou por instituições de educação especial, sem fins lucrativos (BRASIL, 2011). Vale ressaltar que as mudanças oriundas desses decretos contribuíram para a ampliação do debate acerca da publicização dos dados sobre os recursos destinados à educação especial e a seu controle e acompanhamento no âmbito dos sistemas educacionais.

Cabe também destacar que os princípios definidos na atual política do governo federal foram confirmados, em 2010, pela Conferência Nacional de Educação (Conae). A Conae mobilizou, no território nacional, diferentes grupos sociais na discussão de diretrizes e estratégias para a construção do novo 
Plano Nacional de Educação, com vigência de 2014 a 2024 (PNE 2014-2024) (LAPLANE; PRIETO, 2010), em que a educação especial foi contemplada na Meta 4 (BRASIL, 2014a).

Cumpre destacar que as políticas de financiamento e sua gestão sofrem influência das correlações de forças políticas, econômicas e sociais em torno da disputa pelo fundo público, no âmbito do Estado brasileiro, marcado pelas contradições e interesses de diferentes grupos e classes que estão presentes ou podem interferir nos processos de formulação e implementação das políticas educacionais (POULANTZAS, 2000). No âmbito do financiamento da educação especial, observa-se que, historicamente, as políticas formuladas são decorrentes de negociações entre forças expressas por familiares, movimentos sociais nacionais e internacionais, profissionais da educação, representantes políticos, instituições privadas de educação especial e outras, que, em nome da manutenção, efetivação e ampliação dos seus direitos, podem defender diferentes propostas para a aplicação de recursos públicos. Nesse processo de discussão do PNE 2014-2024 ficou evidente a forte capacidade das entidades privadas de influenciar os parlamentares e a opinião pública na garantia da manutenção do financiamento das referidas instituições que atuam por meio de convênios com o Poder Público na provisão de serviços de educação especial (LAPLANE; CAIADO; KASSAR, 2016).

Assim, com o fito de analisar a relação existente entre as políticas de educação especial desencadeadas pelo governo federal e o financiamento da educação, são analisados e discutidos desdobramentos dessas diretrizes para o controle e o acompanhamento dos recursos aplicados à essa modalidade de ensino em um município brasileiro. Antes, porém, delineamos a metodologia do desenvolvimento do estudo.

\section{Percurso metodológico}

No desenvolvimento da pesquisa ${ }^{3}$, foi realizada uma entrevista coletiva semiestruturada para reunir dados complementares às fontes documentais e aos balanços financeiros da Secretaria Municipal de Educação de Vitória (Seme-Vitória), previamente analisados, sobre planejamento orçamentário, receitas e despesas da educação. A entrevista coletiva, com roteiro semiestruturado, foi em 2014.

3 Este trabalho apresenta extrato de resultados de pesquisa de doutoramento finalizada 
realizada, em maio de 2014, com profissionais dos setores da educação infantil, do ensino fundamental e da educação especial, além de gerências administrativas, gestão democrática, recursos humanos, planejamento, formação e secretaria de finanças da Seme-Vitória. Na entrevista coletiva, conforme Kramer e Nunes (2007, p. 430), “[...] os entrevistados falam, dividem opiniões, discutem, trazendo à tona os fatores críticos de determinada problemática [...]", oportunizando condições de se manifestarem sobre a temática em questão.

Antecedendo o início da entrevista, foi dado conhecimento à preservação das identidades e selada a autorização de divulgação dos dados em trabalhos de caráter científico, por meio da assinatura do Termo de Consentimento Livre e Esclarecido.

Para a organização, sistematização e análise das narrativas, gravadas em áudio e transcritas na íntegra, estas foram submetidas a análise de conteúdo, que se trata de um método de tratamento e análise de informações, cujo objetivo é "[...] compreender criticamente o sentido das comunicações, seu conteúdo manifesto ou latente, as significações explícitas ou ocultas" (CHIZZOTTI, 1995, p. 98). Leituras sucessivas do material permitiram selecionar excertos das falas dos gestores que enfatizavam desafios e possibilidades inerentes ao acompanhamento e controle dos recursos públicos voltados à educação especial no município de Vitória/ES, as quais são apresentadas na próxima seção.

\section{O sistema municipal de ensino de Vitória/ES}

Vitória/ES, com $98.194 \mathrm{~km}^{2}$, prioritariamente urbano, tinha população estimada em 327.801 mil habitantes, majoritariamente em idade ativa entre 15 e 64 anos (72,52\%) (PNUD, 2013). O rendimento mensal total domiciliar per capita nominal em 2010 era de $\mathrm{R} \$ 1.866,58$, o que ultrapassava a média nacional (R\$ 1.056,80) (PNUD, 2013).

O sistema municipal de ensino provê como direito a todos o ensino fundamental de nove anos, a educação infantil e as modalidades: educação especial e educação de jovens e adultos - EJA (VITÓRIA, 1998). Em 2014, a rede de ensino era constituída de 53 unidades de ensino fundamental e 48 de educação infantil, tinha 49.227 matrículas, sendo 26.788 no ensino fundamental, 18.436 na educação infantil, 1.063 na educação especial (todos na classe comum, representando $2,2 \%$ do total de matrículas) e 2.940 na EJA (BRASIL, 2014b). A educação especial teve início com os Laboratórios Pedagógicos, criados nos anos 1990, que ofereciam apoio especializado aos alunos com deficiência, TGD e altas 
habilidades/superdotação, em algumas escolas comuns, denominadas "unidades polos", das nove regiões administrativas do município, cujo atendimento era acompanhado e assessorado por equipe da educação especial da Seme-Vitória (GOBETE, 2005). Depois, houve expansão e descentralização de serviços de educação especial com a criação de mais laboratórios e atuação do coordenador de educação especial, vinculado à equipe supracitada, nas escolas, com funções que envolviam: o planejamento das ações desse serviço; o encaminhamento de alunos para a avaliação em instituições conveniadas à Prefeitura Municipal de Vitória (PMV); a organização e a orientação do trabalho dos estagiários; e a articulação das atividades do professor do laboratório e demais profissionais da escola (GOBETE, 2005). Posteriormente, essa estrutura foi substituída por salas de recursos multifuncionais (SRM) sob a coordenação da equipe da gestão da escola, a fim de aprimorar as práticas pedagógicas e disseminar as discussões acerca da educação inclusiva no cotidiano da escola (VITÓRIA, 2008). No ano de 2014, o município possuía 53 SRM, sendo sete na educação infantil (13\% das unidades) e 46 no ensino fundamental ( $87 \%$ das unidades). No plano de trabalho, era enfatizada a necessidade do trabalho colaborativo entre professores de educação especial e da classe comum para o acompanhamento ao aluno em da sala de aula e/ou nos momentos de discussão sobre os processos de aprendizagem dos alunos (VITÓRIA, 2008).

Os quase 280 professores das SRM (VITÓRIA, 2008) com formação especializada, desenvolviam o AEE no contraturno (VITÓRIA, 2008). Eram selecionados, por meio de processo interno, do quadro efetivo da educação infantil ou do ensino fundamental, ou eram admitidos em regime de contratação temporária. Assim, o sistema municipal de ensino de Vitória/ES realizava diversas ações que absorviam recursos e representavam investimento no intuito de efetivar o direito à educação (FRANÇA, 2014), bem como representavam desafios à gestão.

\section{Gestão do financiamento da educação especial em Vitória: desafios e possibilidades}

O primeiro desafio apontado pelos gestores refere-se à especificação das despesas da educação especial nos demonstrativos financeiros da Seme-Vitória. Após a análise dos registros de despesas correntes ${ }^{4}$, em particular as despesas

4 Despesas correntes (despesa de custeio) estão relacionadas à manutenção e funcionamento dos serviços públicos em geral; despesas de capital, vinculadas ao aspecto financeiro dos gastos 
com pessoal, pode-se constatar que os valores despendidos com os profissionais da educação especial não estavam descritos. Essa é uma das consequências de a inexistência de cargo para professor especializado ingressar por meio de concurso público, pois a inexistência da classificação funcional impedia (ou dificultava) a discriminação desses professores do total de profissionais que atuavam na educação infantil e/ou no ensino fundamental, como já mencionado. De acordo com a-entrevistada:

[...] uma das dificuldades que nós enfrentamos é exatamente por não ter separadamente [...] educação especial, educação de jovens e adultos [...] esse é o exercício que nós vamos ter que fazer, porque no nosso balanço isso está junto. (Subsecretária de Gestão).

Essa necessidade de especificação dos gastos de pessoal é reiterada por outros estudos (VIEIRA, 2014; DI PIERRO, 2000) que analisaram o financiamento da EJA e evidenciaram que as despesas com essa modalidade estavam agregadas às das outras etapas de ensino, contribuindo para sua invisibilidade nas prestações de contas.

Ficou claro nas entrevistas que o mesmo acorria relativamente às despesas de custeio, aquelas dirigidas à manutenção e ao desenvolvimento do ensino:

[...] temos a mesma dificuldade que você [pesquisadora] encontrou quando verificou o que era despesa com material didático, [...] em relação ao percentual de despesa da educação especial e das outras modalidades dentro da educação básica. Você não tem como desatrelar o que vai para a educação especial. (Subsecretária de Gestão da Seme-Vitória).

Em continuidade, refletiram sobre a necessidade de garantir visibilidade às despesas destinadas à essa modalidade de ensino por meio da desagregação dos gastos com etapas da educação básica e a modalidade educação especial, visto que está vinculada ao orçamento e/ou gastos da educação infantil e ensino fundamental no âmbito dos sistemas de ensino. Corrobora esse procedimento contábil a concepção de educação inclusiva a qual entende o aluno com deficiên-

governamentais, “[...] com a intenção de adquirir ou construir bens de capital que contribuirão para a produção ou geração de novos bens que integrarão o patrimônio público" (CRUZ et al., 2001, p. 28). 
cia, TGD e altas habilidades/superdotação como parte da escola e/ou sistema e beneficiário das melhorias desenvolvidas na educação geral (VIEGAS, 2014). Essa compreensão pode apoiar a especificação das despesas dessa modalidade na prestação de contas e/ou balanço financeiro e pode invisibilizar os gastos nessa área e a necessidade de investimentos mais elevados para prover materiais, equipamentos e outros profissionais especializados requeridos por alguns desses alunos, com vistas a lhes possibilitar o acesso ao conhecimento escolar (VIEGAS, 2014).

Os dados financeiros da pesquisa de FRANÇA (2014) mostraram que a educação especial teve participação nas despesas do custeio da Seme-Vitória, no período de 2008 a 2014, na proporção de aproximadamente 0,4\%. Essa constatação poderia nos levar a afirmar, como Prieto e Gil (2011, p. 96), que "[...] o custeio da educação especial não é mais caro, proporcionalmente, do que o custeio das demais etapas e modalidades". Entretanto, o fato de as despesas com pessoal não terem sido registradas nos demonstrativos do município porque estavam diluídas nas outras etapas da educação básica, conforme constado na referida pesquisa, pode sustentar a hipótese de que os valores de custeio da educação especial podiam estar subdimensionados.

Em relação às despesas de capital ${ }^{5}$, o município não gastou com compra de equipamentos e materiais permanentes para a educação especial no período analisado, segundo os dados cedidos pela Secretaria Municipal de Fazenda (FRANÇA, 2014). Esse tipo de despesa tinha valor zerado em 2008 e ínfimos em $2009(0,01 \%)$ e 2010.

Contudo, não se pode concluir que Vitória/ES nada tenha investido na educação especial, posto que as despesas de capital podem ter sido contabilizadas em outras etapas de ensino ou ter sido utilizadas verbas de outras fontes que não foram registradas nessa rubrica. Como descreve a gestora:

[...] no processo de compra, você não tem como desatrelar [os gastos]. Em anos anteriores, no Plano Plurianual ${ }^{6}$ e nos orçamentos, os programas estavam tão separadinhos que acabavam não promovendo a execução; porque você não vai abrir um processo de compra [de] mobiliário só da

5 Despesas de capital se referem aos gastos governamentais, “[...] com a intenção de adquirir ou construir bens de capital que contribuirão para a produção ou geração de novos bens e integrarão o patrimônio público" (CRUZ et al., 2001, p. 28).

6 O Plano Plurianual (PPA) define diretrizes, objetivos e metas da administração para um período de quatro anos, com ações orçamentárias e custos da administração pública, para as despesas de capital e outras delas decorrentes, e para as relativas aos programas de duração continuada (POLO, 1999). 
educação especial! [Se] você vai comprar mobiliário, dentre eles, mesa adaptada, cadeira adaptada, ai você compra [os da educação especial]. [...] como você desatrela isso?

[...] outro exemplo: quando você está fazendo investimento em acessibilidade física, que tem um objetivo claro [...], na hora de computar isso, ele está num contrato maior, de manutenção, e está inserido no programa do ensino fundamental, melhoria da qualidade, ou seja, no geral. Quanto disso está vinculado ao desenvolvimento da política de educação especial? (Subsecretária de Gestão).

Nesse relato, a gestora enfatizou a complexidade que envolvia a especificação dos valores e a desagregação das despesas relacionadas à educação especial do que era destinado às outras etapas e modalidades de ensino no balanço da Seme-Vitória. Ressaltou ainda o processo moroso da administração pública no processo de compra de materiais e equipamentos para uma única modalidade de ensino e destacou que, quando esse material era especificado em um programa, as despesas se tornavam visíveis no momento dos balanços financeiros, facilitando o seu acompanhamento e controle.

As falas dos gestores apontam o desconhecimento de outras possibilidades de realização do registro dos dados financeiros referentes a educação especial, diante de uma forma padronizada estabelecida pela administração pública que, historicamente, desconsiderava o financiamento para as modalidades de ensino. Evidenciam-se, assim, que os desafios relativamente ao processo da garantia de transparência dos recursos voltados à educação especial não se restringem apenas a procedimentos técnicos (embora essa dimensão possa se constituir como um entrave, especialmente se o profissional não tiver formação política, técnica e operacional para dominar esses trâmites e suas consequências), ou à discussão sobre as vantagens e desvantagens na desagregação dos elementos de despesas com as modalidades de ensino, no âmbito dos balanços financeiros da administração municipal, mas também envolvem interesses políticos e econômicos que se beneficiam do não controle dos recursos públicos.

Cumpre destacar que a gestão democrática está prevista na CF/1988 e na LDB (BRASIL, 1996, art. 72), no qual também foi destacada a obrigatoriedade do Poder Público de publicizar as informações de arrecadação e despesa em educação e o cumprimento da vinculação de recursos. Aqueles destinados à educação especial também deveriam ser registrados nos relatórios de execução orçamentária e nos procedimentos contábeis das contas públicas dos respectivos entes federados, no intuito de garantir visibilidade das receitas e despesas e o acompanhamento e controle de sua aplicação na educação brasileira. 
Como possibilidades, durante a entrevista coletiva, os gestores elencaram alguns procedimentos que poderiam contribuir para o controle dos recursos da educação especial no âmbito do município, tendo em vista que os seus registros nos balanços financeiros da Seme-Vitória eram diluídos nos da educação infantil e do ensino fundamental e que não havia nenhuma orientação normativa e/ou legal indicando a necessidade de desagregação.

Vale ressaltar que a ausência da educação especial no "Manual de Demonstrativos Fiscais: aplicados à União, Estados, Distrito Federal e Municípios" (BRASIL, 2014b), elaborado pela Secretaria do Tesouro Nacional, que orienta a União, o Distrito Federal, os estados e os municípios quanto à elaboração dos relatórios e procedimentos contábeis das contas públicas, contribui para que gestores deixem de registrar a alocação de recursos nessa modalidade de ensino, bem como para a sua invisibilidade nas receitas e despesas destinadas à manutenção e desenvolvimento do ensino, o que impossibilita o acompanhamento e controle dos recursos públicos da educação especial no âmbito do Estado brasileiro.

Nesse cenário, os gestores enfatizaram a importância e a necessidade de alterar a forma de registro desses dados nos demonstrativos de despesas e sugeriram a especificação das despesas da educação especial no âmbito da educação infantil e do ensino fundamental e nas modalidades de ensino. $\mathrm{O}$ gestor da gerência de planejamento da Seme-Vitória, ao reportar-se às despesas de capital, organizadas por etapa e modalidade de ensino, sugere:

[...] ao invés de indicar o total de despesa de capital em educação especial, ela [a educação especial] deveria ter um campo dentro da educação infantil ou do ensino fundamental para esses custos, porque, olha só, se o mobiliário é especifico você tem como saber [...].

De acordo com sua fala, tal procedimento evidenciaria os gastos na educação especial e garantiria sua visibilidade no balanço financeiro municipal.

Outra possibilidade seria melhorar, no processo de elaboração do planejamento orçamentário, a articulação entre o PPA, a Lei de Diretrizes Orçamentárias $(\mathrm{LDO})^{7}$, a Lei Orçamentária Anual $(\mathrm{LOA})^{8}$ e a contabilidade pública,

7 A LDO se pauta nos grandes princípios e critérios apontados no PPA, visto que ela antecipa a discussão orçamentária, define metas e prioridades para o ano seguinte e anuncia as metas fiscais, ou seja, o montante a ser arrecadado e como este será despendido; sua vigência é de um ano (POLO, 1999).

8 A LOA deve estimar as receitas de tributos e fixar as despesas que as administrações públicas da União, dos estados e dos municípios estão autorizadas a executar no exercício financeiro (POLO, 1999). 
na tentativa de garantir o registro e a transparência dos recursos destinados à educação especial. Nas palavras de uma das entrevistadas: " [...] a gente precisa melhorar isso. Tem que haver um casamento entre o como a gente elabora os programas no PPA, ano a ano nos orçamentos, com a própria contabilidade pública [...]." (Subsecretária de Gestão).

Essa fala nos indica a importância de os recursos aplicados à educação e de todas as demais despesas do Poder Público estarem previstos no planejamento orçamentário. Entretanto, de acordo com Polo (1999), o orçamento tem sido pouco utilizado como uma das etapas conceituais do processo de planejamento para alocação racional e gerencial de recursos públicos, visando à prestação de serviços à população. Na mesma direção, Salvador (2010, p. 178) salienta que o "[...] orçamento não se limita a uma peça técnica e formal ou a um instrumento de planejamento; ele é, desde suas origens, uma peça de cunho político". Assim, as decisões orçamentárias refletem a correlação de forças sociais e políticas da sociedade, posto que decorre de negociações relacionadas ao financiamento do Estado no âmbito do Executivo e do Legislativo, servindo como instrumento de controle, bem como para a definição de prioridades de gastos com políticas públicas.

Os gestores apontaram ainda a necessidade de eles desenvolverem estudos por escola da rede municipal de ensino de Vitória (RME-Vitória/ES) para chegar a um custo aluno aproximado nessa modalidade de ensino, tendo satisfeitas e identificadas as suas necessidades específicas. Consoante a isso, um gestor ressalta:

[...] voltando a sua questão da separação do custo, isso deve ter alguma importância em questão contábil [...] não seria possivel [...] você pegar uma escola como piloto e analisar [se] o custo aluno da educação especial [...] é [...] maior do que um custo de um aluno que não é da educação especial? Ai você separa isso e o restante [e] quando [...] tiver o custo, [...] divide per capita com outros alunos. Isso talvez seria uma forma de você conseguir separar isso [...] (Gerente de Planejamento).

Embora não possamos afirmar a viabilidade da possibilidade de desenvolvimento de estudos voltados à definição do custo aluno da educação especial a partir do contexto da escola, como propõe o gerente, é preciso desenvolver estudos voltados à identificação e análise dos custos do atendimento de alunos público-alvo da educação especial de modo a garantir seu direto à educação por meio do reconhecimento e atendimento de suas necessidades específicas. 
Ou ainda, para fazer aproximações ao custo-aluno qualidade que seria, de acordo com Oliveira (2007, p. 110), “[...] o valor monetário que expressaria a quantidade de bens e serviços necessários por aluno para que se tenha um ensino de qualidade".

Outra possibilidade tangenciada na fala do gestor é garantir formação continuada aos profissionais que atuam em secretarias de educação, na tentativa de aprimorar a gestão dos recursos educacionais no âmbito da administração pública.

Cumpre destacar que a produção sobre custo/aluno da educação especial é ínfima se comparada ao número significativo de pesquisas (PINTO, 2006) da educação básica. Pesquisas sobre custo/aluno de educação especial (CARDOSO, 1997; MOREIRA; CARVALHO, 2011) indicam seu custo elevado e a necessidade de mais estudos.

No desenvolvimento da discussão sobre os recursos da educação especial, o profissional da Gerência de Planejamento ressaltou, ainda, a possibilidade de chegar, a partir de estudos realizados em escolas, a um valor aproximado do custo/aluno: "[...] acredito ser possível você chegar aos percentuais, até para você investir mais em escola que tem o maior número [de alunos com deficiência, TGD e altas habilidades/superdotação]".

O gestor reconhece a importância em especificar as despesas com a educação especial, na tentativa de contribuir ao aprimoramento das políticas de financiamento dessa modalidade. Contudo, faz-se necessário ressaltar que a adoção de tais estudos analíticos pressupõe investimento econômico em condições técnicas, políticas para seu desenvolvimento. Outra sugestão é a articulação intra e intersetorial, envolvendo profissionais dos setores da administração pública municipal de educação, e destes com os das demais secretarias municipais, especialmente os da Fazenda e da Administração, de modo a garantir a visibilidade dos gastos no âmbito da educação básica.

Nesse sentido, ficou evidente no desenrolar dessa entrevista com os profissionais que integravam setores da RME-Vitória/ES, imbricados no financiamento, a complexidade, bem como os desafios e possibilidades de aprimoramento da gestão da educação especial no âmbito desse município.

\section{Algumas considerações}

Ao discutirmos percepções dos gestores do município de Vitória/ES, implicados com financiamento em âmbito da Seme-Vitória, em relação aos recursos 
destinados à educação especial e ao seu processo de controle, acompanhamento e transparência no âmbito das contas públicas, evidenciamos desafios e possibilidades imbricadas nesse processo complexo de produção e publicização de dados referentes aos recursos educacionais. Essas ações são indispensáveis à projeção dos recursos necessários à sua ampliação e aprimoramento na estrutura do Estado brasileiro.

Esse percurso abrange a dificuldade de acesso aos dados, a compreensão da linguagem contábil e a sua complexa forma de registro, bem como os procedimentos vinculados à publicização de informações acerca das verbas públicas destinadas à educação, no âmbito da estrutura da administração pública. Nesse sentido, os gestores apontaram as dificuldades que envolvem, desde os procedimentos de especificação dos elementos da educação especial à sua desagregação das outras etapas e modalidades da educação básica, bem como a sua configuração e articulação no planejamento orçamentário.

Cumpre destacar ainda que, no processo de diálogo e reflexão, que se desenvolveu no momento da entrevista coletiva, na Seme-Vitória, os gestores participantes também apontaram possibilidades referentes ao financiamento da educação especial. Sugeriram mudanças na forma de registros das despesas no âmbito de cada etapa e modalidade de ensino; articulação com o planejamento orçamentário; desenvolvimento de estudo nas escolas para averiguar o custo/ aluno do atendimento de alunos com deficiência, TGD e altas habilidades/ superdotação em sistemas de ensino com orientação inclusiva; bem como o fomento a articulações entre secretarias envolvidas no processo de gestão de políticas públicas.

Os participantes da entrevista coletiva apontaram ações que não se restringem a mudanças técnico-administrativas, mas a alterações políticas que envolvem a configuração da gestão pública e seus procedimentos para controle, acompanhamento e transparência do uso de recursos públicos voltados à educação especial. A elaboração e implementação de políticas públicas pressupõem investimentos por parte do Estado na tentativa de assegurar direitos sociais conquistados pela população com deficiência, TGD e altas habilidades/superdotação, em particular no que tange ao acesso, à permanência e à qualidade de ensino nos sistemas educacionais brasileiros. Por fim, esse texto vislumbra a importância da continuidade de desenvolvimento de estudos sobre o financiamento da educação especial no intuito de contribuir com a constituição e/ou compreensão das políticas e ações voltadas à essa área no Brasil. 


\section{REFERÊNCIAS}

BENATTI, M. M. S. O financiamento público das instituições não-estatais de educação especial em Campo Grande (2001-2005). In: CONGRESSO BRASILEIRO MULTIDISCIPLINAR DE EDUCAÇÃO ESPECIAL E VII ENCONTRO DAASSOCIAÇÃO BRASILEIRA DE PESQUISADORES EM EDUCAÇÃO ESPECIAL, 6., 2011. Paraná. Anais... Paraná: UEL, 2011. p. 3478-3488.

BRASIL. Congresso Nacional. Constituição [da] República Federativa do Brasil. Brasília: Senado Federal, 1988.

BRASIL. Congresso Nacional. Lei de Diretrizes e Bases da Educação Nacional - LDB n $^{\circ}$. 9.394, de 20 de dezembro de 1996. Diário Oficial [da] República Federativa do Brasil, Brasília, 23 dez. 1996.

BRASIL. Conselho Nacional de Educação. Câmara de Educação Básica. Resolução CNE/ CEB nº. 2, de 11 de setembro de 2001. Diretrizes Nacionais para a Educação Especial na Educação Básica. Diário Oficial [da] República Federativa do Brasil, 14 set. 2001. Seção 1E, p. 39-40.

BRASIL. Congresso Nacional. Emenda Constitucional n ${ }^{\circ} .53$, de 19 de dezembro de 2006. Dá nova redação aos arts. 7, 23, 30, 206, 208, 211 e 212 da Constituição Federal e ao art. 60 do Ato das Disposições Constitucionais Transitórias. Diário Oficial [da] República Federativa do Brasil, Brasília, DF, 20 dez. 2006. Seção 1, p. 5.

BRASIL. Presidência da República. Lei no. 11.494, de 20 de junho de 2007. Regulamenta o Fundo de Manutenção e Desenvolvimento da Educação Básica e de Valorização dos Profissionais da Educação - FUNDEB, de que trata o art. 60 do Ato das Disposições Constitucionais Transitórias; altera a Lei $\mathrm{n}^{\circ}$. 10.195, de 14 de fevereiro de 2001; revoga dispositivos das Leis $n^{\circ} .9 .424$, de 24 de dezembro de 1996, nº 10.880 , de 9 de junho de 2004, e n ${ }^{\circ} .10 .845$, de 5 de março de 2004; e dá outras providências. Diário Oficial [da] República Federativa do Brasil, Brasília, 21 jun. 2007a.

BRASIL. Presidência da República. Decreto no. 6.253, de 13 de novembro de 2007. Dispõe sobre o Fundo de Manutenção e Desenvolvimento da Educação Básica e de Valorização dos Profissionais da Educação - FUNDEB, regulamenta a Lei nº 11.494 , de 20 de junho de 2007, e dá outras providências. Diário Oficial [da] República Federativa do Brasil, Brasília, 14 nov. 2007b. Seção 1, p. 18.

BRASIL. Ministério da Educação. Política Nacional de Educação Especial na Perspectiva da Educação Inclusiva. Brasil: MEC/SEESP, 2008.

BRASIL. Conselho Nacional de Educação. Câmara de Educação Básica. Resolução CNE/CEB n ${ }^{\circ} .4$, de 2 de outubro de 2009. Diretrizes operacionais para o atendimento educacional especializado na educação básica, modalidade educação especial. Diário Oficial [da] República Federativa do Brasil, 5 out. 2009. Seção 1, p. 17. 
BRASIL. Presidência da República. Decreto nº 7.611, de 17 de novembro de 2011. Dispõe sobre a educação especial, o atendimento educacional especializado e dá outras providências. Brasília: Presidência da República, 2011. Diário Oficial [da] República Federativa do Brasil, Brasília, 18 nov. 2011. Seção 1, p. 12.

BRASIL. Congresso Nacional. Lei no 13.005, 25 de junho de 2014. Aprova o Plano Nacional de Educação - PNE e dá outras providências. Diário Oficial [da] República Federativa do Brasil, Brasília, 26 jun. 2014a. Seção 1, p.1.

BRASIL. Ministério da Educação. Instituto Nacional de Estudos e Pesquisas Educacionais Anísio Teixeira (INEP). Censo Escolar da Educação Básica - 2014. Brasília, DF: MEC/ Inep, 2014b. Disponível em: <http://www.inep.gov.br/web/guest/resultados-e-resumos>. Acesso em: 21 nov. 2017.

CARDOSO, D. G. M. Custos da educação especial: análise comparativa do custo/ aluno em escola da rede municipal do Rio de Janeiro. 1997. Dissertação (Mestrado em Educação) - Programa de Pós-Graduação em Educação, Universidade Católica de Brasília, Brasília, 1997.

CHIZZOTTI, A. Pesquisa em ciências humanas e sociais. São Paulo: Cortez, 1995.

CRUZ, F. et al. Comentários à Lei no . 4.320. 2. ed. São Paulo: Atlas, 2001.

DI PIERRO, M. C. O financiamento público da educação de jovens e adultos no Brasil no período de 1985/1999. In: REUNIÃO ANUAL DAASSOCIAÇÃO NACIONAL DE PÓS-GRADUAÇÃO E PESQUISA EM EDUCAÇÃO, 23, 2000, Anais... Caxambu. Disponível em: <http://www.anped.org.br>. Acesso em: 16 abr. 2014.

FRANÇA, M. G. Financiamento da educação especial: complexas tramas, permanentes contradições e novos desafios. 2014. Tese (Doutorado em Educação) - Programa de Pós-Graduação da Faculdade de Educação, Universidade de São Paulo, São Paulo, 2014.

GARCIA, R. M. C.; MICHELS, M. H. A política de educação especial no Brasil (19912011): uma análise da produção do GT15 - educação especial na Anped. Revista Brasileira de Educação Especial, Marília, v. 17, p. 105-124, maio/ago. 2011.

GOBETE, G. Politica educacional no município de Vitória no periodo de 1989 a 2004 : implicações nas políticas de educação especial. 2005. 199 f. Dissertação (Mestrado em Educação) - Programa de Pós-Graduação em Educação, Universidade Federal do Espírito Santo, Vitória, 2005.

GONZALEZ, R. K.; PRIETO, R. G. Financiamento da educação especial em município paulista: algumas aproximações com o tema. In: CONGRESSO BRASILEIRO DE EDUCAÇÃO ESPECIAL E VII ENCONTRO NACIONAL DOS PESQUISADORES DA EDUCAÇÃO ESPECIAL, 5., 2012, São Carlos, Anais... São Carlos: UFSCar, 2012, p. $7475-7488$.

KRAMER, S.; NUNES, M. F. Gestão pública, formação e identidade de profissionais da educação infantil. Cadernos de Pesquisa, São Paulo, v. 37, n. 131, p. 423-454, maio/ ago. 2007. 
LAPLANE, A. L. F. de; PRIETO, R. G. Inclusão, diversidade e igualdade na Conae 2010: perspectivas para o novo Plano Nacional de Educação. Educação \& Sociedade, Campinas, v. 31, n. 112, p. 919-938, jul./set. 2010.

LAPLANE, A. L. F. de; CAIADO, K. R. M.; KASSAR, M. de C. M. As relações público-privado na educação especial: tendências atuais no Brasil. Revista Teias, v. 17, n. 46, p. 40-55, jul./set. 2016.

MOREIRA, L. C.; CARVALHO, A. P. de. Custo Aluno Qualidade inicial (CAQi) para alunos com deficiência incluídos no ensino medido público de Curitiba. In: SIMPÓSIO BRASILEIRO DE POLÍTICA E ADMINISTRAÇÃO DA EDUCAÇÃO, 25, 2011. São Paulo. Anais... São Paulo: PUC, 2011. p. 1-12.

OLIVEIRA, R. P. de. O financiamento da educação. In: OLIVEIRA, R. P de; ADRIÃO, T. (Org.). Gestão Financiamento e direito à Educação: análise da Constituição Federal e da LDB. 3. ed. São Paulo: Xamã, 2007. p. 83-122.

PINTO, J. M. de R. Uma proposta de custo-aluno-qualidade na educação básica. 2006. Disponível em: <http://seer.ufrgs.br/index.php/rbpae/article/view/18877>. Acesso em: 07 dez. 2017.

PNUD - Programa das Nações Unidas para o Desenvolvimento. Atlas do Desenvolvimento Humano no Brasil. 2013. Disponível em: < http://www.pnud.org.br>. Acesso em: 6 abr. 2014.

POLO, J. C. Planejamento e orçamento no município. In: PRASEM, FUNDESCOLA, MEC. Guia de Consulta. Brasília: MEC, 1999. p. 295-329.

POULANTZAS, N. O Estado, o poder, o socialismo. São Paulo: Paz e Terra, 2000.

PRIETO, R. G.; GIL, I-J.-P. C. Gestão das políticas de atendimento aos alunos com necessidades educacionais especiais em municípios paulistas. Relatório de Pesquisa. São Paulo: Faculdade de Educação - USP, 2011.

SALVADOR, E. Fundo público e seguridade social no Brasil. São Paulo: Cortez, 2010.

VIEGAS, L. T. A reconfiguração da educação especial e os espaços de atendimento educacional especializado: análise da constituição de um centro de atendimento em Cachoeirinha/RS. 2014. Tese (Doutorado em Educação) - Programa de Pós-Graduação em Educação, Universidade Federal do Rio Grande do Sul, Porto Alegre, 2014.

VIEIRA, R. Expectativas e frustações: a inclusão da EJA no Fundeb. In: ENCONTRO DA ASSOCIAÇÃO DE PESQUISA EM FINANCIAMENTO DA EDUCAÇÃO, 2 ., 2014. Paraná. Anais... Paraná: UFPR, 2014. p. 94-108.

VITÓRIA. Lei $n^{\circ}$. 4.747, de 27 de julho de 1998. Institui o sistema municipal de ensino do município de Vitória. Disponível em: <http://sistemas/vitoria.es.gov.br/webleis/leis/ arquivos/1998/L4747.pdf>. Acesso em: 05 maio 2012. 
FRANÇA, M. G.; PRIETO, R. G. Financiamento da educação especial no município de Vitória...

VITÓRIA. Plano de Trabalho-2008/2009. Vitória, ES: SEME/SPP/CFAEE - Coordenação de Formação e Acompanhamento à Educação Especial, 2008.

Texto recebido em 01 de maio de 2018. Texto aprovado em 03 de junho de 2018. 